\title{
A Method of Investigating the Ageing Perception and Satisfaction towards Product Appearances
}

\author{
A. Zuhairi A. Majid ${ }^{1}$, Nurazlina Jamalludin ${ }^{2}$ \\ ${ }^{1}$ School of The Arts, Universiti Sains Malaysia, Penang, Malaysia \\ ${ }^{2}$ School of The Arts, Universiti Sains Malaysia, Penang, Malaysia \\ zuhairi.majid@usm.my,nurnania@hotmail.com
}

\begin{abstract}
The purpose of this paper is to proposing a method investigating on product appearance perceived by the ageing consumers. It also examines the relationship between ageing perception towards product appearance in order to better understand how they will respond to products as they grow older. A general literature review was conducted in an effort to identify the significant, substantive work to date. The data obtained in this study were collected from a questionnaire survey involving 45 to 65 year old academician from local universities. Descriptive analysis was performed to analyze the respondents' perception and satisfaction towards product appearances. Finally, suggestions are made as a way forward to identify the product appearance attributes and where can be considered by designers, marketers or researchers in designing a product for ageing population. With the availability of this method and by understanding the needs of aging the researchers or designers, thereby can produce a quality and better product design requirements that meet and will fulfil the consumer needs. There is a need to study the ageing and the relationship to product development, specifically in the appearance of the product.
\end{abstract}

Keywords: Ageing, consumers, product appearance, satisfaction, product design and development

\section{Introduction}

Ageing population remains a global phenomenon and has changed the demographic profile of many countries. Today, every second two people will reach the age of 60 by 2030, $16 \%$ of the world's population will be over 60 . By 2035 in Malaysia will be an ageing nation, when $15 \%$ of the population are classified as senior citizens. Thus the proportion of the elderly is increasing. Minister Datuk Seri Rohani Abdul Karim said a forecast by the statistics department revealed that Malaysia's citizen would number 5.6 million by 2035 . Although the stage of the increase in older populations is still not as stunning as other developing countries but demographic transition phenomena are experienced (Izyan Idris \& Sudbury-Riley, 2010) . For Malaysia, coping with population ageing can be a great challenge (Ong \& Phillips, 2007). Since the rise of this generation is becoming an issue, many sectors have to take an action to improve the wellbeing of the ageing particularly in the consumerism aspect in product design development. Despite the importance of this study is for understanding the aging and developing better ways to serve older consumers. Research on this issue in Malaysia, particularly still infancy and relatively limited.

This paper provides a literature review on different aspects of ageing perception of product appearance in order to better understand how they will respond to products as they grow older. This paper begins by briefing about ageing in Malaysia then followed by reviewing ageing as a consumer. However, the intention is not to discuss or seeking descriptions of bio-logical or sociological ageing. Finally, it focused on the aspects of ageing perception of product appearance in different context. By reviewing existing work and presenting it is hoped that the following benefits will be realized. Having considered these issues, suggestion are made so that designers may pay more attention as they design for ageing consumer's that will meet their needs for the future.

\section{Literature Reviews}

Changes in the age structure of the population can be seen from the population pyramid in chart 1 below. In 2010, the shape of Malaysia population pyramid is regressive and is expected to remain until 2040. The 
regressive population pyramid has a smaller base which indicates a low birth rate and the convex slopes which reflects that the adult popula-tion mortality rate is low. In 2040, the pyramid shows a flat and boarder apex indicating a rise in the elderly population.

The population of elderly in 2040 is expected to in-crease and doubled compared to 2010. This indicates that ageing is increasing in Malaysia and elder consumer might increase proportional to the population projected by the Department of Statistics Malaysia. At this point, the con-sumers will not only the youngsters, but the elderly as well. The focus can now be shifted to the elderly consumers.

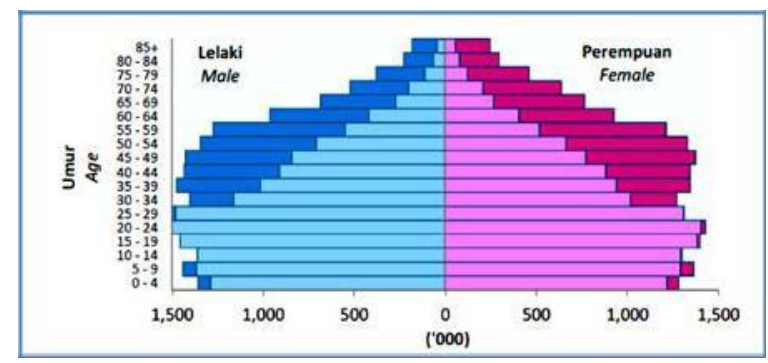

Figure 1: Malaysia population pyramid 2010-2040 Source: Department of statistic Malaysia

Malaysia's health ministry defines seniors as those aged 60 years and above and the determination of this age lower than the age adopted by the world health organization (WHO) of 65 years. (Lim, Xin, Sulaiman, \& Baldry, 2013) state that in Malaysia, there is no specific provision of law defining the term of elderly. Now ageing cannot be measured based on age alone as "chronological age" does not represent "physiological age". In other words, the physical and mental capabilities of the elderly can be changed. The issues and the effects of aging is the increase in life expectancy in the elderly occur because there is progress in medical science and technology, improving quality of life, decrease mortality rates, the decline in fertility, increased levels of education and increase the importance of health. This means that many of the issues faced by individuals who may have serious consequences and disastrous for the country (Iv et al., 2009).

People or government in Malaysia, concern about the issues mentions, but what about the product that will support them in their daily life. Increasing age also causes physical and psychological changes mean the daily product also is important in helping them to survive and to help them manage in daily life. Besides all the issues mentioned above, good lifestyle including a healthy diet and a healthy social life, have adequate rest, hygiene and good environment etc also important. In addition, (Iv et al., 2009) stated that more than half of the elderly in this country live alone without family. The aging problem is not only a concern among the sectors involved and policy makers, but it is also a concern among those aged itself due to some challenges to be confronted of their life in their golden years.

On the other hand, in the policy statement, the senior citizens of the country are the government's commitment to create a self-sufficient elderly, dignified and respected by optimizing self-potential through healthy aging, positive, active, and productive and support to improve the wellbeing in developing countries.

\subsection{Ageing as a consumer}

The rapid ageing of the world population has numerous implications for product design. As the proportion of the population born in baby - boomers years of 1946-1964 advances into the older age groups over the next decade or so, their changing needs are likely to become economically important for marketers. According to (Bloom, Canning, \& Sevilla, 2003) the ageing issues will influence the productivity and economic growth of the nation.

The growth of the older generation is estimated to increase up to two times numbers of children from 2010 to 2035 specifically in Malaysia. Particularly with the rise of this generation, consumerism aspect in product design development will be affected in order to cater to this market. The increasingly larger population of ageing makes it difficult for marketers, too, to ignore the segment's attractiveness (Ong \& Phillips, 2007). For ageing consumer, new technology products have the potential to make life easier, to support communication with family and friends, to assist with health care, and to help them remain safe and functionally independent in their later years of life (Dickinson \& Hill, 2007). Technology is one way of assuring their continued well-being. As stated by Medeiros ACB et al (2008), promoting social integration and independent life through technology is a way of im-proving older adults' wellbeing, and important in order to keep the resources that are required to provide special care at sustainable levels. Product design has been recognized as an opportunity for differential advantage in the marketplace (Creusen M, Schoormans J, 2005) . The satisfaction level of ageing consumer in perceiving a product design are very important and has become an important issue as many factors to take into consideration depending on their condition and lifestyle.

\section{Stage 1}

\begin{tabular}{ll}
\hline Purpose & $\begin{array}{l}\text { To identify the preferable products } \\
\text { for evaluation }\end{array}$ \\
\hline $\begin{array}{l}\text { Subjects } \\
\text { Material }\end{array}$ & $\begin{array}{l}\text { Academician : Age 45-65: 450 } \\
\text { Questionaires } \\
\text { Analytical tool }\end{array}$ \\
& Descriptive analysis \\
\hline
\end{tabular}

Stage 2 


\begin{tabular}{ll}
\hline & Semantic Differential Scale \\
\hline Purpose & To measure respondents \\
& satisfaction level and To study \\
& respondents perception towards \\
& product attributes \\
\hline Subjects & Academician : Age 45-65: 450 \\
Material & Questionaires \\
Analytical tool & Descriptive analysis \\
\hline
\end{tabular}

\subsection{Product appearance}

There are various literature related to product appearance. Product visual appearance plays an important role in determining user response (Crilly, Moultrie, \& Clarkson, 2004). When a user sees a product appearance, the user considers the specific physical properties that together form a product design such as color, shape and texture (Blijlevens, Creusen, \& Schoormans, 2009). Supported by and added by Bloch (1995), Veyisoglu (2010), these elements include the perceptual characteristics of a product, such as shape, scale, tempo, proportion, material, color, reflection, decoration, and texture.

(Creusen \& Schoormans, 2005) recognizes product appearance can have aesthetic and symbolic values for the user, can deliver functional features and give quality impression (functional value), and communicate easily with ease (ergonomic value) and in addition, attractive attention and can affect the ease of product categorization. Their study distinguishes six characters that appear to be relevant to users and sufficient to illustrate the effect of product appearance on product choices. In a similar manner, (Jamalludin, Md.hashim, \& Zalay@zali, 2014) focused on the appearance of colour on a particular brand of product which responded to customer choices. The study explore if colour elements influences customer choices in product appearance by asked to indicate an opinion on impression, emotion and appreciation to understand the customer perception towards physical of product which involved colour from the particular brand. This was done by concluding that the understanding of colour choice and responses of consumer for various products has become very complicated because consumers have developed a wide range of colour associations for various products. Colours carry as much symbolic power as the specific objects of the design.

The appearance of a product influences the consumer product choice in several ways (Schumacher, 2007, Jamalludin, et al 2014). Furthermore, product appearance can provide a satisfaction to a consumer and as stated by (Creusen M, Schoormans J, 2005) many people like to buy a product that looks aesthetically pleasing and the visual appearance of a product can influence consumer product evaluation and choice in several ways. According to
Berkowitz (1987), Veyisoglu (2010), especially in aggressive price markets, design variants of size, colour, shape, packaging, features and accessories (i.e., product appearance) are a basic means for creation of the differential advantage which sells new products and enables firms to cope with demographic, social, cultural and economic changes (Berkowitz 1987). It is clear all the opinion on a product attribute are relevant and the visual element meaningful to physical of product. This is significant because product appearance plays a role in determining consumer response. Along with this, the product experience such as aesthetic, meaning and emotional experience explained the personal and nature of the product. There has been much research and discussion conducted on this topic, but still lack of study focusing on this topic on ageing as a respondent particularly in Malaysia. More research is required to gain a better understanding as ageing population is growing.

\section{Problem Statement}

The progress of ageing and product design research in this area has been limited and still new especially in Malaysia. Most of the research has been done in Malaysia are focusing on social welfare, retirement, medical services, economic and other facilities for ageing. Hence, the issues clearly highlights, especially in providing adequate facilities, infrastructure and healthcare for the senior citizens (Lim et al., 2013). For instance, in other countries such as United Kingdom, Canada and a few Asian countries such as Japan, China have been doing research on product development for ageing ages ago. In relation to that, there is a need on this issue to be studied and there is an impact on the ageing population in Malaysia to support their activities in daily life.

\section{Methodology}

The research project as summarised in table 1 are divided into two stages, stages 1 and 2 . In stage 1 , is to identify the products for evaluation and the preferable or most chosen products were used for the stage 2 where the respondents satisfaction level and the perception towards products attributes were evaluate.

\subsection{Stage 1}

In stage 1, in order to identify the products to be assessed in the second stage, four categories of products and which each category has two options. Subjects: the subject sample used at this stage are academician aged between 45 to 65 years old. The subjects represented the ageing population. Material: The questionnaires are used at this stage and 
respondents are asking to indicate the preferable products from 8 samples given (figure 1) contains conventional and modern product. Results:From 8 products, 4 was chose as a preferable products and to be evaluate at the stage 2 (figure 2).

\begin{tabular}{|l|l|}
\hline & $\begin{array}{l}\text { Product A } \\
\text { Toothbrush } \\
\text { Option 2 }\end{array}$ \\
Product A \\
Oothbrush \\
Option 1
\end{tabular}

Figure 1: The 8 sample of products for stage 1

\subsection{Stage 2}

In stage2, study serves as more direct test by examining the satisfaction level and perception towards product attributes. The SD method was used to explore the respondents perception towards product attributes and to measure the satisfaction level towards the products. Subjects: Academician aged between 45 to 65 years old participated in this stage. Material: In this questionnaires, 4 products been evaluate and respondents are asked to indicate their satisfaction level towards the products with a
7 point scale with 7 means satisfied and 1 score means unsatisfied. The respondents perception towards products are based on 7 product attributes which scored according to a 7- point scale too. A bipolar pair of adjective defines the attribute scale. On this evaluation scale, a score of 9 means respondents has a very positive impression, meanwhile a 1 point means disagree has a very negative impression. Procedure: The questionnaire was distributed to the respondents through web survey and email. The respondents were asked to express their feeling towards the product been evaluate by indicate the 7 point scale. The attributes to evaluate are 1) Appearance: Boring Interesting, 2) Colour: Warm - Cool 3) Ease Of Use: Difficult - Easy, 4) Function: Complicated Uncomplicated, 5) Size: Small - Big, 6) Shape: Geometric - Organic.

\section{Results and Discussion}

Data collected were analyses using Social Package for Social Sciences (SPSS) software version 20. Descriptive statistics were obtained for all the variables in the study.

\subsection{Result for stage 1}

The result for stage 1 as shown in table 1 , show that Product A - option 1 is the most

preferable product with score $68 \%$ of the respondents. For product B- option 1 with $50.9 \%$ and product $\mathrm{C}$ - option 1 with $63.6 \%$. For product D respondents tend to choose option 2 as a preferable product with $48.4 \%$ of the respondents. Most of the respondents prefer conventional products probably because they used to it.

Table 1: Result of preferable products

\begin{tabular}{llll}
\hline Product & $\begin{array}{l}\text { Frequency } \\
(\mathbf{n = 4 5 0})\end{array}$ & $\begin{array}{l}\text { Percent } \\
(\boldsymbol{\%})\end{array}$ & Mean \\
\hline Product A & & & \\
A1 & 306 & 68.0 & 1.1883 \\
A2 & 71 & 15.8 & \\
Product B & & & \\
B1 & 229 & 50.9 & 1.3844 \\
B2 & 143 & 31.8 & \\
Product C & & & \\
C1 & 286 & 63.6 & 1.2332 \\
C2 & 87 & 193 & \\
Product D & & & \\
D1 & 153 & 34.0 & 1.5876 \\
D2 & 218 & 48.4 & \\
\hline
\end{tabular}




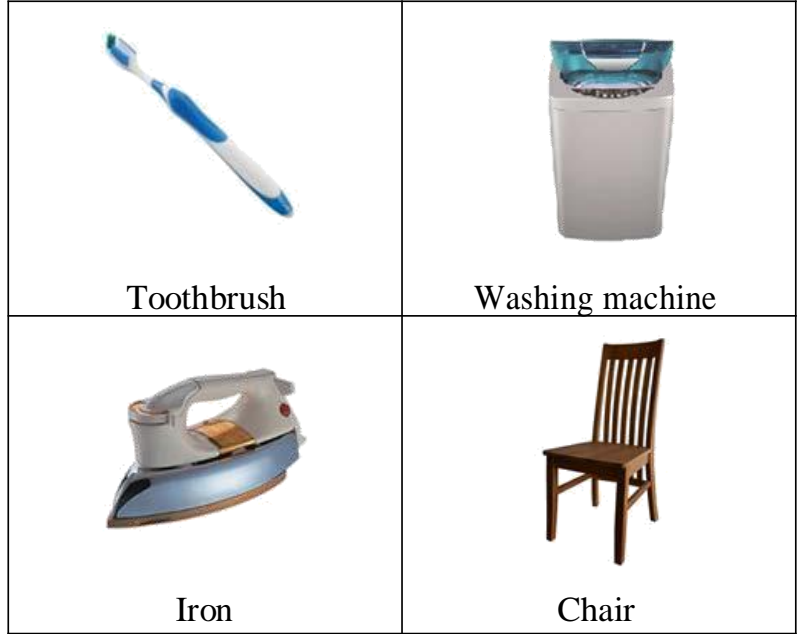

Figure 2. The 4 samples of product for evaluation in stage 2

From the result above, the preferable products chose by respondents will be used as products to be evaluated for the product attributes on the questionnaire (Figure 2).

Figure 3 shows the results of satisfaction level, where it is apparent that respondents are satisfied with almost all 4 products (A, B, C, D) by selecting 5 and 6 scale. Only a small percentage of respondents with a scale of 3 and below are unsatisfied with the selected product.

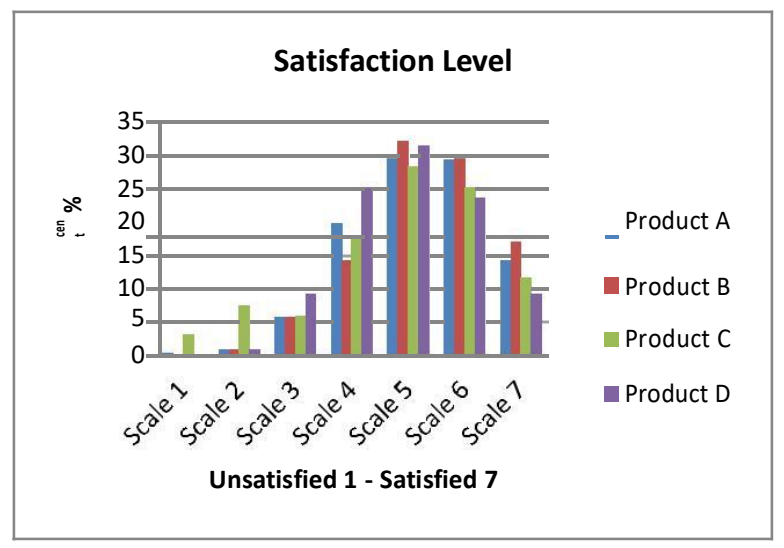

Figure 3. Percentage of Product Satisfaction Level

The appearance of the products in figure 4 shows that evaluation of product B and D are interesting on scale 6 by $60 \%$ of respondents. Meanwhile, $24 \%$ of respondents think product $\mathrm{A}$ is quite boring and $27 \%$ on scale 2 think product $\mathrm{C}$ is boring.

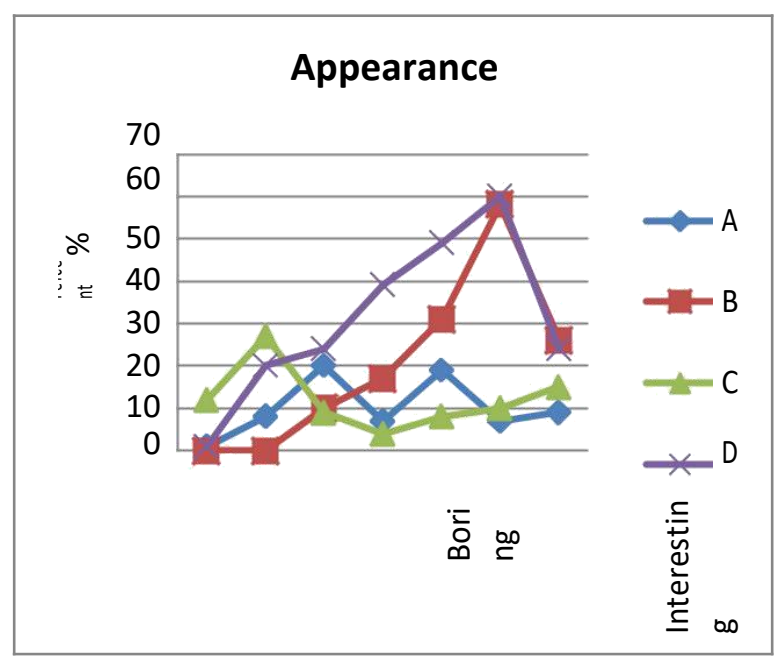

Figure 4. Appearance of the products

The result in figure 5 shows that the selection of product A and B is aimed at cool with $24 \%$ and $45 \%$ on the scale 5 . While $28 \%$ of the respondents stated that product $\mathrm{C}$ is warm color on the scale 2 and product $\mathrm{D}$ is in between cool and warm color.

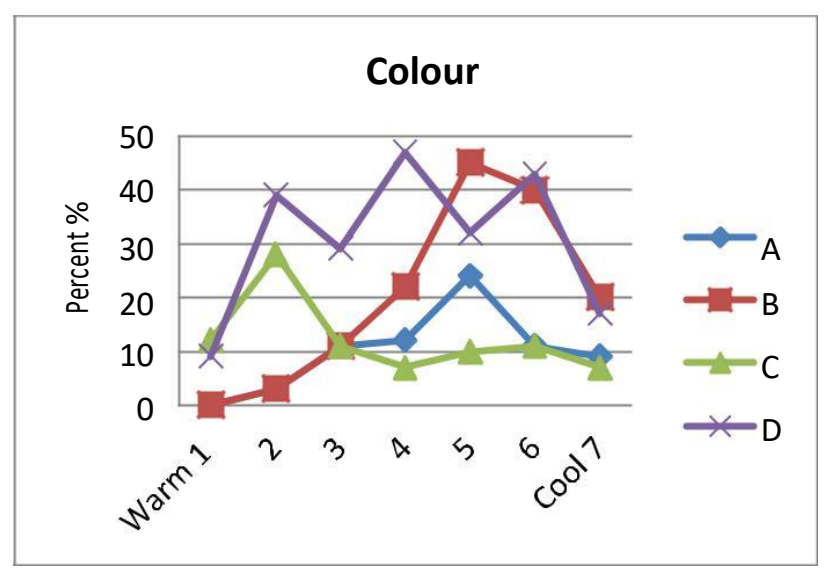

Figure 5. Color attribute of the products

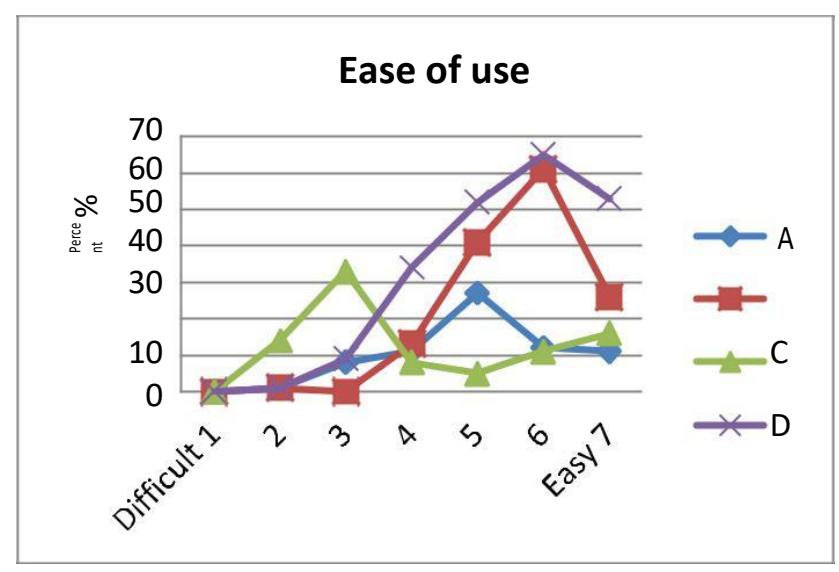

Figure 6. Ease of use attribute of the products 
Ease of use attributes of the products in figure 6 shows that the use of products $\mathrm{A}, \mathrm{B}$ and $\mathrm{D}$ shows that they are easy to use with a positive scale of 5 and 6 while the chart shows that product $\mathrm{C}$ is slightly quite difficult to handle.

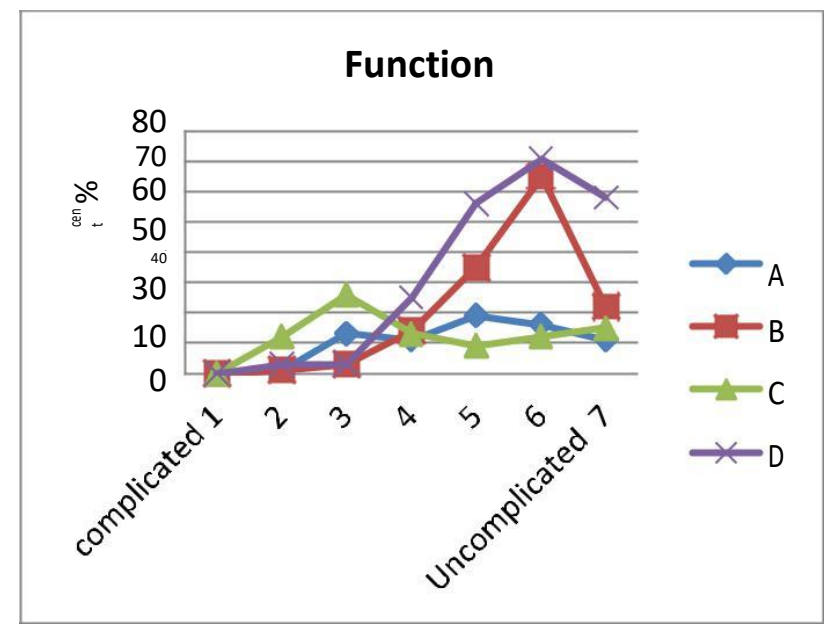

Figure 7. Function attribute of the products

Figure 7 illustrates the results of function attribute of the products. Based on the chart, evaluation of function product B and D are uncomplicated with $65 \%$ and $71 \%$ on scale 6 . Meanwhile, $19 \%$ of respondent consider that function of product $\mathrm{A}$ is slightly uncomplicated to operate. However, $26 \%$ states that product $\mathrm{C}$ is somewhat complicated.

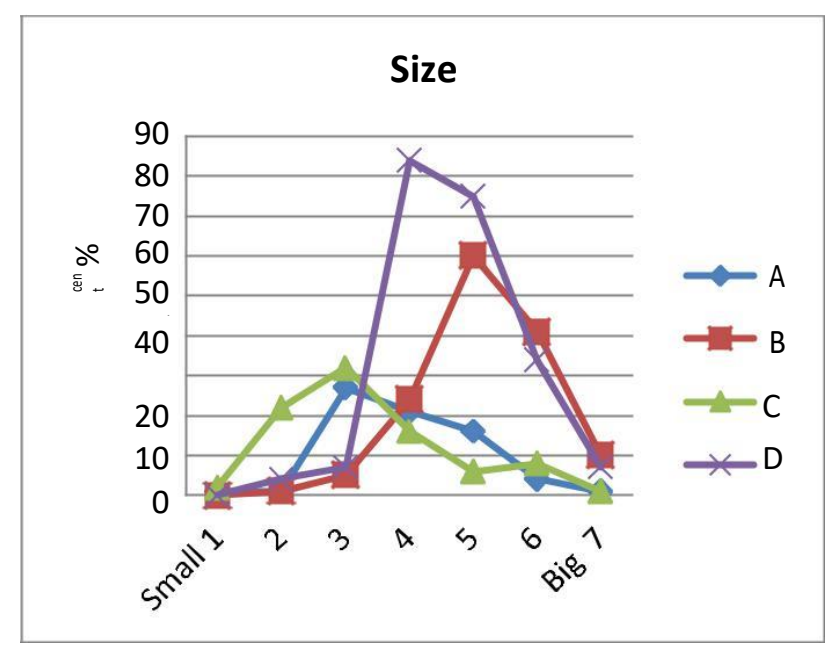

Figure 8. Size attribute of the products

Size of a product plays a role and in figure 8 shows respondents agree that product $\mathrm{B}$ are relatively large and product $\mathrm{D}$ is just nice which is not too big and too small. Product $\mathrm{A}$ and $\mathrm{C}$ respondents agree that size of the product is small.

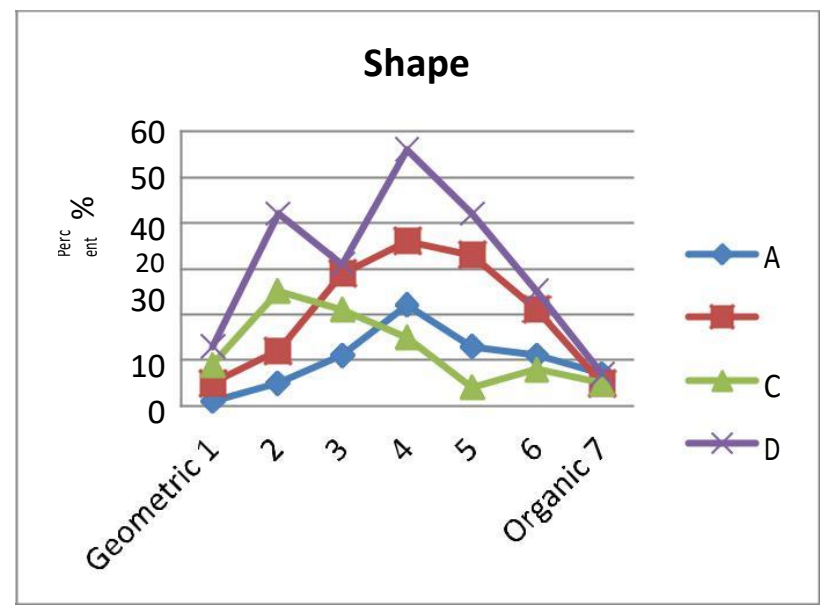

Figure 9. Shape attribute of the products

Figure 9 illustrates the results of shape attribute of the products. Based on the chart, product A shows that $22 \%$ of respondents think that the product has both organic and geometric shape. For product B on scale 4 and 5 with $69 \%$ of respondents evaluate the product is in organic shape. Meanwhile, $25 \%$ on scale 2 of respondents think that product $\mathrm{C}$ is more geometric shape. However, $56 \%$ states that product $\mathrm{D}$ is in between geometric and organic.

Through the study, results revealed that respondents have different views for each product being evaluated. Based on the data collected from the survey conducted, product A has features such as its relatively boring product, cool colors, easy to use, the function is slightly uncomplicated, small size and has an organic and geometric shape. Therefore, for B products, the appearance is quite interesting, cool colors; easy to use, uncomplicated function, large size and shape are organic. Respondents think that product $\mathrm{D}$, although it is wood but still attractive, the color is not too warm and not too cool, easy to use and uncomplicated function, the size are just nice and has balance shape in between organic and geometric. According to Khairul,A.Zuhairi \& Nazlina (2010) that design is primarily involved with the delivery of ideas to the market while trends movement of product characteristics has significant relationship throughout the decades. The "form follows function" has dominated in design concepts are relevant until today that relates to the physical needs.

Throughout the discussion, the overall attributes of the product such as the color of the products also found as an influencing factor in selecting a product. Cool color is a selection and warm color is optional. The product should also be easy to use so as not to burden the old user. In terms of function, respondents prefer uncomplicated and easy to operate the product. Size should be suitable for products and shapes that have both organic and geometric shapes to be preferred. 


\section{Conclusion}

This study examines the relationship between ageing perception towards product appearance so as to better understand how they will respond to products as they grow older. As results showed, ageing consumers have their own interpretation of how products should be developed. In conclusion, the respondents think that the product to be produced should have an attractive appearance to use. These results suggest that in order to create a product for an ageing population, designers need to pay more attention to the attributes of products. Products are created according to the users' needs and to meet user requirements to achieve their satisfaction towards products design.

\section{ACKNOWLEDGMENTS}

We would like to thank you to the Dean of School of Arts, University Sains Malaysia for supporting this paper to be presented at Bandung Creative Movement International Conference 2017. The contents of this paper are solely the responsibility of the authors and do not necessarily represent the official views of the sponsor.

\section{REFERENCES}

[1] A. Veyisoglu (2010). The influence of product appearance on perceived product quality in reference to washing machines.

[2] Berkowitz, Marvin. 1987. Product Shape as a Design Innovation Strategy. Journal of Product innovation Management 4(4):274-283.

[3] Blijlevens, J., Creusen, M. E. H., \& Schoormans, J. P. L. (2009). How consumers perceive product appearance: The identification of three product appearance attributes. International Journal of Design, 3, 27-35.

[4] Bloch, P. H. 1995. Seeking the Ideal Form: Product Design and Consumer Response, in: Journal of Marketing, Vol. 59, No.3, pp.16-29.

[5] Bloom, D. E., Canning, D., \& Sevilla, J. (2003). The Demographic dividend: a new perspective on economic consequences of population change.

[6] Creusen, M. E. H., \& Schoormans, J. P. L. (2005). The different roles of product appearance in consumer choice. Journal of Product Innovation Management. doi:10.1111/j.0737-6782.2005.00103.
[7] Crilly, N., Moultrie, J., \& Clarkson, P. J. (2004). Seeing things: Consumer response to the visual domain in product design. Design Studies,25,547-577. doi:10.1016/j.destud.2004.03.001

[8] Desmet, P., \& Hekkert, P. (2007). Framework of product experience. International Journal of Design, 1(1), 57-66.

[9] Fàbregues, S. (@ sfabreguesf). (2013). Fàbregues, Sergi (@sfabreguesf).

[10] Idris, I., \& Sudbury-Riley, L. (2010). The representation of older adults in malaysian advertising. International Journal of Aging \& Society.

[11] Iv, P. P., Of, E., Life, I., In, E., Aini, N. O. R., Idris, H. J., \& Abu, N. (2009). Kesan peningkatan jangka hayat di malaysia, 1, 305-315.

[12] Jamalludin, N., Md.hashim, A., \& Zalay@zali, abdul aziz. (2014). Customer choice of colour element in relation to physical product appearances. Jurnal Seni Dan Pendidikan Seni, 2, 118-130.

[13] Khairul A.A., A., A.Zuhairi, A., \& Nazlina, S. (2010). Wealth Creation through Service Innovation Design in Malaysia. International Joint Conference on Design Yonsei University (p. 4). Wonju: KSDS, ADADA, KSID.

[14] Lim, W., Xin, W., Sulaiman, N., \& Baldry, D. (2013). A conceptual framework for understanding the social care facilities management audit (SCFMA) at the residential care home for the elderly ( RCHFE ) in Malaysia. Proceedings of 2nd International Conference on Management, Economics and Finance, (October), 112-140.

[15] Ong, fon sim, \& Phillips, david r. (2007). Older Consumers in Malaysia, 2(1), 85-117. 